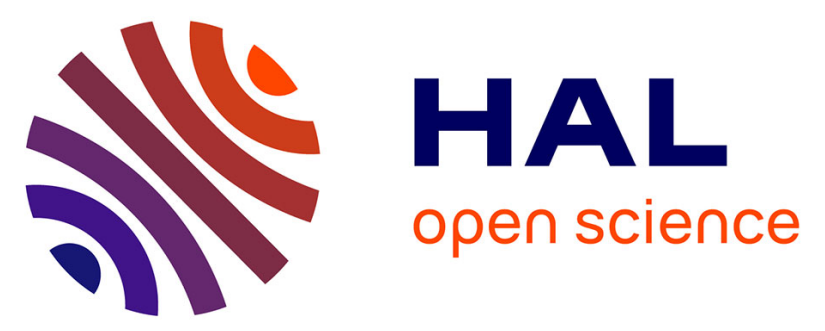

\title{
Pivotal Role of a Pentacoordinate 3MC State on the Photocleavage Efficiency of a Thioether Ligand in Ruthenium(II) Complexes: A Theoretical Mechanistic Study
}

Adrien J. Göttle, Fabienne Alary, Martial Boggio-Pasqua, Isabelle M. Dixon, Jean-Louis Heully, Azadeh Bahreman, Sven H.C. Askes, Sylvestre Bonnet

\section{To cite this version:}

Adrien J. Göttle, Fabienne Alary, Martial Boggio-Pasqua, Isabelle M. Dixon, Jean-Louis Heully, et al.. Pivotal Role of a Pentacoordinate 3MC State on the Photocleavage Efficiency of a Thioether Ligand in Ruthenium(II) Complexes: A Theoretical Mechanistic Study. Inorganic Chemistry, 2016, 55 (9), pp.4448-4456. 10.1021/acs.inorgchem.6b00268 . hal-01327047

\section{HAL Id: hal-01327047 https://hal.science/hal-01327047}

Submitted on 25 Feb 2020

HAL is a multi-disciplinary open access archive for the deposit and dissemination of scientific research documents, whether they are published or not. The documents may come from teaching and research institutions in France or abroad, or from public or private research centers.
L'archive ouverte pluridisciplinaire $\mathbf{H A L}$, est destinée au dépôt et à la diffusion de documents scientifiques de niveau recherche, publiés ou non, émanant des établissements d'enseignement et de recherche français ou étrangers, des laboratoires publics ou privés. 
Inorg. Chem. 2016, 55, 4448

DOI: 10.1021/acs.inorgchem.6b00268

\title{
Pivotal Role of a Pentacoordinate ${ }^{3}$ MC State on the Photocleavage Efficiency of a Thioether Ligand in Ruthenium(II) Complexes: A Theoretical Mechanistic Study
}

\author{
Adrien J. Göttle, ${ }^{\mathrm{a}}$ Fabienne Alary, ${ }^{\mathrm{a}}$ Martial Boggio-Pasqua, ${ }^{\mathrm{a}}$ Isabelle M. Dixon, ${ }^{\mathrm{a}}$ Jean-Louis \\ Heully, ${ }^{a}$ Azadeh Bahreman, ${ }^{b}$ Sven H. C. Askes, ${ }^{b}$ and Sylvestre Bonnet ${ }^{b}$ \\ ${ }^{a}$ Laboratoire de Chimie et Physique Quantiques, UMR 5626, IRSAMC, CNRS et Université \\ de Toulouse, 118 route de Narbonne, 31062 Toulouse, France \\ ${ }^{\mathrm{b}}$ Leiden Institute of Chemistry, Leiden University, Einsteinweg 55, 2333 CC Leiden, The \\ Netherlands
}

\begin{abstract}
A mechanistic study of the photocleavage of the methylthioethanol ligand (Hmte) in the series of ruthenium complexes $[\mathrm{Ru}(\mathrm{tpy})(\mathrm{N}-\mathrm{N})(\mathrm{Hmte})]^{2+}\left(\mathrm{tpy}=2,2^{\prime}: 6^{\prime}, 2^{\prime \prime}\right.$-terpyridine, $\mathrm{N}-\mathrm{N}=$ bpy (2,2'-bipyridine), biq (2,2'-biquinoline), dcbpy (6,6'-dichloro-2,2'- bipyridine), dmbpy (6,6'-dimethyl-2,2'-bipyridine)) was performed using density functional theory. These studies reveal the decisive role of two quasi-degenerate triplet metal-centered states, denoted ${ }^{3} \mathrm{MC}_{\text {hexa }}$ and ${ }^{3} \mathrm{MC}_{\text {penta }}$, on the lowest triplet potential energy surface. It also shows how the population of the specific pentacoordinate ${ }^{3} \mathrm{MC}_{\text {penta }}$ state, characterized by a geometry more accessible for the attack of a solvent molecule, is a key step for the efficiency of the photosubstitution reaction. The difference in the photosubstitution quantum yields experimentally observed for this series of complexes (from $\varphi=0.022$ for $\mathrm{N}-\mathrm{N}=$ bpy up to $\varphi=0.30$ for $\mathrm{N}-\mathrm{N}=\mathrm{dmbpy}$ ) is rationalized by the existence of this ${ }^{3} \mathrm{MC}_{\text {penta }}$ photoreactive state and by the different topologies of the triplet excited-state potential energy surfaces, rather than by the sole steric properties of these polypyridinyl ligands.
\end{abstract}




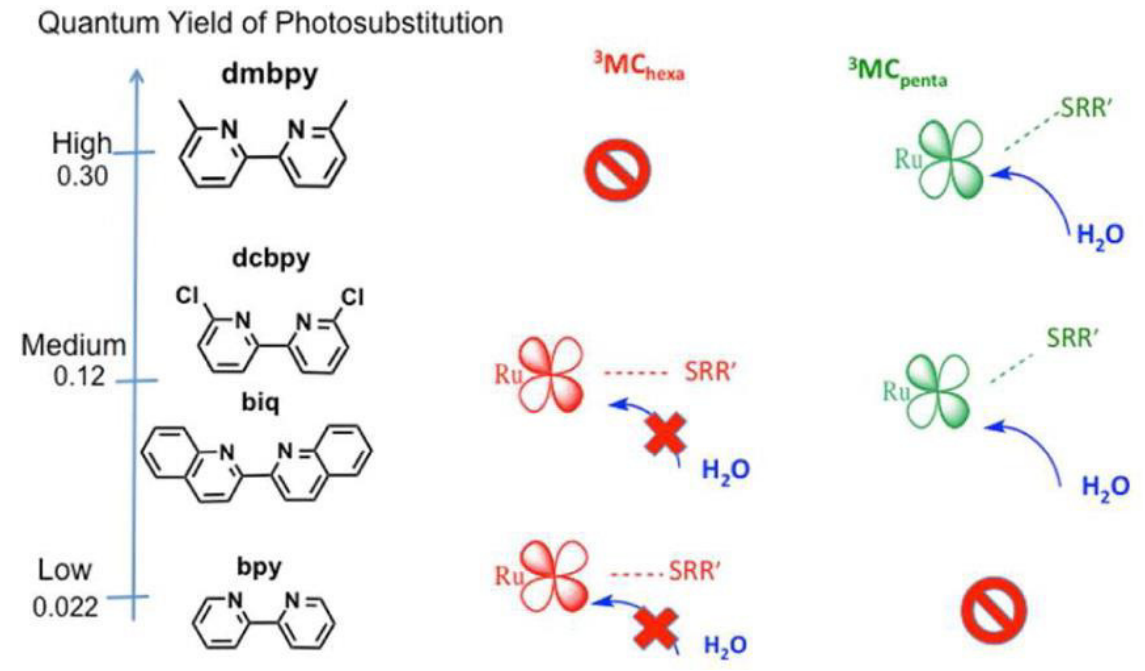




\section{Introduction}

The photochemistry of ruthenium complexes has attracted much attention due to their potential as light-activatable anticancer agents, emissive probes, or photoactivable synthons and prodrugs. ${ }^{1}$ Under visible light irradiation, some ruthenium complexes are found to undergo photochemical substitution processes, as shown in Scheme 1, in which one of the ligands in the coordination sphere is replaced by a solvent molecule. Nevertheless, due to the size of the complexes and as far as their intimate photosubstitution mechanisms are concerned, few detailed theoretical studies have been performed, although recent methodologies based on density functional theory (DFT) have opened new opportunities to shed light on the microscopic mechanism displayed in Scheme $1 .^{2}$

Scheme 1. Photosubstitution of the Hmte ligand by an aqua ligand (top) and ligand structures (N-N) used in this work (bottom) ${ }^{\mathrm{a}}$

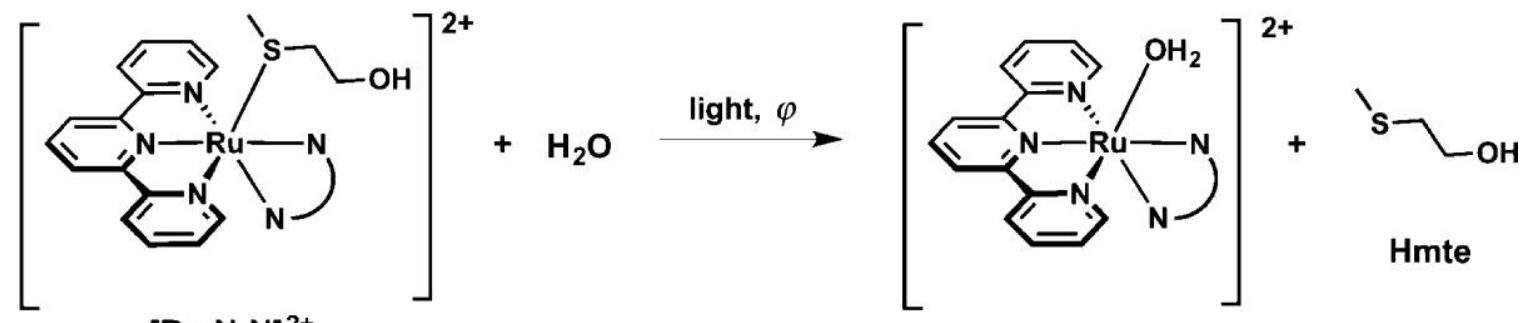

$[\mathrm{Ru} N-\mathrm{N}]^{2+}$

$\mathbf{N}-\mathbf{N}=$
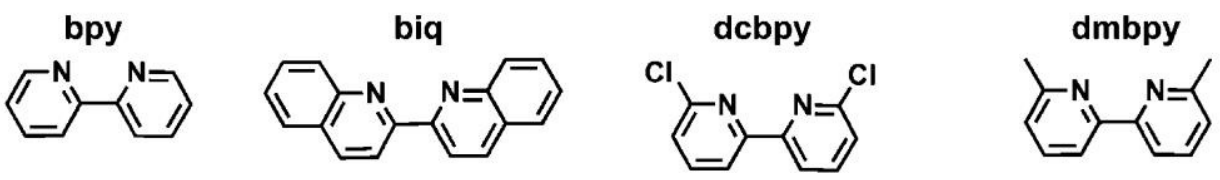

$\mathrm{a}_{\varphi}$ is the quantum yield of photosubstitution.

In this work we focus on the detailed mechanism for the photocleavage of a monodentate ligand in a family of $[\mathrm{Ru}(\operatorname{tpy})(\mathrm{N}-\mathrm{N})(\mathrm{L})]^{2+}$ complexes, where tpy $=2,2^{\prime}: 6^{\prime}, 2^{\prime \prime}$ - terpyridine, N-N $=$ bpy (2,2'-bipyridine), biq (2,2'-biquinoline), dcbpy (6,6'-dichloro-2,2'-bipyridine), dmbpy (6,6'- dimethyl-2,2'-bipyridine), and L = Hmte (2-methylthioethanol) (Scheme 1). Hereafter the common Ru(tpy)(Hmte) fragment will be abbreviated Ru. In this family of molecules, the quantum yield $\varphi$ for the photosubstitution of Hmte by a water molecule depends on the bidentate N-N ligand. ${ }^{3 b}$ Previous experimental studies have proposed the correlation of an increased photosubstitution quantum yield $\varphi$ with the presence of sterically hindered N-N ligands. ${ }^{3}$ In the classical picture this photochemical reactivity is indeed based on the presence 
of low-lying metal-centered excited states $\left({ }^{3} \mathrm{MC}\right)$, characterized by the promotion of an electron from a metallic $\mathrm{d}$ orbital to an antibonding metal-ligand $\sigma$ orbital $\left(\mathrm{d} \sigma^{*}\right)$ and thus by adequate geometries that can lead to ligand exchange. Visible light irradiation of such ruthenium complexes generates a metal-to- ligand charge transfer $\left({ }^{3} \mathrm{MLCT}\right)$ excited state that can deactivate either by radiative means (by emitting a photon) or by population of a nearby ${ }^{3} \mathrm{MC}$ state. ${ }^{4}$ To improve the population of the photoreactive ${ }^{3} \mathrm{MC}$ state, a classical strategy consists of the introduction of sterically bulky ligands in the coordination sphere of the metal. Indeed, the presence of such bulky ligands is usually acknowledged to decrease the ligand field by decreasing the overlap between the $\mathrm{Ru} \mathrm{d}$ orbitals and the pyridine nitrogen lone pairs. In a low ligand field the ${ }^{3} \mathrm{MC}$ states are more accessible, and several experimental reports demonstrate that in such complexes the efficiency of ligand photosubstitution is indeed enhanced. ${ }^{3}$

From a mechanistic point of view it is usually postulated, considering the limited experimental proofs for the existence of intermediates with an increased or reduced coordination number (hepta- or pentacoordinated intermediates), ${ }^{5}$ that the ground-state substitution of monodentate ligands L by solvent molecules operates by an interchange mechanism in which the weakening of the initial $\mathrm{Ru}-\mathrm{L}$ bond is more or less concerted with the formation of the $\mathrm{Ru}-$ solvent bond. ${ }^{6}$

The aim of the present investigation is first to see whether the classical picture of the photoreactivity of polypyridyl ruthenium complexes is consistent with the topology of the triplet excited state potential energy surface $\left({ }^{3} \mathrm{PES}\right)$ for this family of complexes. The second objective is an attempt to rationalize the much higher photoreactivity of $[\mathbf{R u} \mathrm{dmbpy}]^{2+}(\varphi=$ $0.30)$, in comparison to that of $[\mathbf{R u} \text { biq }]^{2+}$ or $[\mathbf{R u} \mathrm{dcbpy}]^{2+}(\varphi=0.12$ and 0.13 , respectively).

The article is organized as follows: first, the ground states of the four complexes are studied in order to detect a possible steric hindrance effect on the geometries and on the molecular orbital diagrams. Then, we discuss the TD-DFT absorption spectra of the four complexes and we assign the main electronic transitions. Finally, the lowest triplet PES with characteristic connecting points for the four species are reported to discuss the formation and the fate of intermediates involved in the photochemical cleavage of the Hmte ligand upon irradiation (Scheme 1). Although the calculation of the absorption spectra of such complexes is routine, the computation of the excited state relaxation pathways and their interpretation remain challenging. All of this information contributes to shedding light on the difference in photoreactivity of the four complexes. 


\section{Computational methods}

All of the calculations were performed using the Gaussian $09^{7}$ and Orca $3.0^{8}$ program packages. DFT calculations were carried out using the hybrid-type Perdew-Burke-Ernzerhof exchange correlation functional ${ }^{9}$ (PBE0) together with Grimme's D3(BJ) ${ }^{10}$ model to add molecular mechanics damped dispersion. We used a triple- $\zeta$ quality basis set, including one polarization function, for $\mathrm{C}, \mathrm{N}, \mathrm{O}, \mathrm{S}$, and $\mathrm{Cl}$ atoms (Ahlrichs TZVP) ${ }^{11}$ and a double- $\zeta$ quality basis set also including one polarization function for hydrogen atoms (Ahlrichs SVP). For the ruthenium atom, a Stuttgart relativistic small-core effective potential with its associated polarized basis set including two $f$ and one $g$ polarization functions was used. ${ }^{12}$ The choice of PBE0 and of the basis set is based on previous works performed on $\left[\mathrm{Ru}(\mathrm{bpy})_{2}(\mathrm{DMSO})_{2}\right]^{2+}$ complexes. ${ }^{13}$ Solvent effects (water) were taken into account in geometry optimization calculations using the polarized continuum $\operatorname{model}^{14}(\mathrm{PCM})$ as implemented in $\mathrm{G} 09$, and all stationary points were characterized as minima or transition states (TSs) using analytical harmonic vibrational frequency calculations. Unrestricted DFT calculations were performed to optimize structures on the lowest triplet PES.

TD-PBE0 calculations were performed to compute the first 20 singlet vertical electronic excitations in water using the conductor-like screening model (COSMO). ${ }^{15}$ These calculations were performed on the ground state (GS) optimized structures in water. Plots of the intensity vs excitation energy were obtained with the orca_mapspc program that applies a Gaussiantype line shape function to the calculated transition with a defined full width at half-maximum of $1200 \mathrm{~cm}^{-1}$. The nature of the transitions was determined using natural transition orbitals. ${ }^{16}$ Computations of the enthalpic and entropic corrections at $298 \mathrm{~K}$ allow the calculation of the activation energies of the photodissociation processes in water. In order to describe deactivation funnels along this pathway, we searched for minimum energy crossing points (MECPs) between the ground and lowest triplet states with Orca. Triplet excited states and MECPs were optimized with PBE0-D3 in the solvent phase.

Optimization of the minimum energy path and calculation of the TSs connecting the two ${ }^{3} \mathrm{MC}$ states, found in the case of $[\mathbf{R u} \text { biq }]^{2+}$ and $[\mathbf{R u} \text { dcbpy }]^{2+}$, have been performed with PBE0-D3 by using the nudged elastic band $(\mathrm{NEB})^{17}$ method associated with the STRING ${ }^{18}$ module implemented in the NWChem ${ }^{19}$ package.

\section{Results and discussion}


Ground state geometrical and electronic structures. The structures of the fully optimized GS structures of the four complexes are shown in Figure 1 along with the numbering of some key atoms. The main structural parameters of the studied complexes in their GS and in their lowest triplet states $\left({ }^{3} \mathrm{MLCT}\right.$ and $\left.{ }^{3} \mathrm{MCs}\right)$ are gathered in Table 1. Further information on the optimized structures can be found in Tables S1-S5, S7, S8, S10-S12, S14-S16, and S18 in the Supporting Information. In the unhindered complex $[\mathbf{R u} b p y]^{2+}$, the terpyridine and the bidentate ligands are planar and lie perpendicular to each other. In contrast, in the three other complexes the bulkiness of the substituted bidentate ligand prevents this optimal geometry. The distortion of the octahedral geometry around the $\mathrm{Ru}$ atom is highlighted by the angle defined by the mean planes of the tpy and N-N ligand. This angle is $89.7^{\circ}$ in the unhindered $[\mathbf{R u} \text { bpy }]^{2+}$ complex (a value of $90^{\circ}$ is expected for a perfect octahedral geometry). The resulting angles in the three other hindered complexes are 58.8, 62.8, and $63.8^{\circ}$. These smaller values illustrate the more distorted geometries of $[\mathbf{R u} b i q]^{2+},[\mathbf{R u} \mathrm{dcbpy}]^{2+}$, and $[\mathbf{R u}$ dmbpy $]^{2+}$.

Figure 1. Structure of $[\mathbf{R u} b p y]^{2+}$ with atom labeling and definition of the mean planes of the tpy and N-N ligands (biq ligand). $\mathrm{H}$ atoms have been removed for clarity.

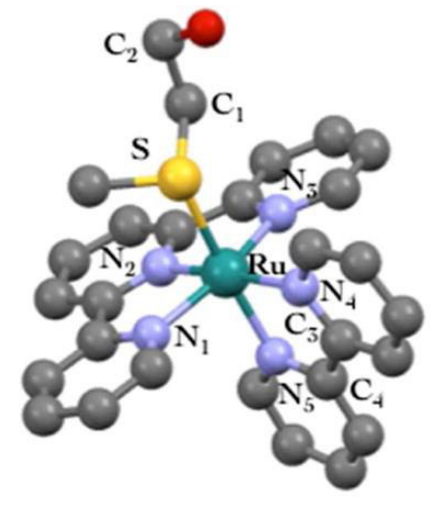

$[\mathbf{R u} b p y]^{2+}$

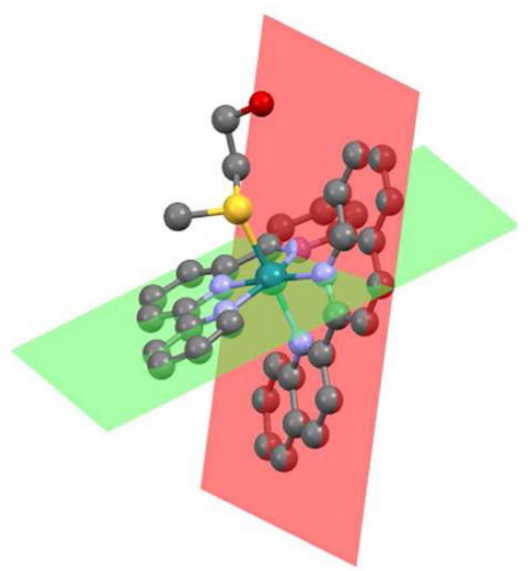

$[\mathbf{R u} b i q]^{2+}$

The computed metal-ligand bond lengths are reported in Table 1 together with angles that are relevant for the discussion (see Figure 1 for atom numbering). The maximum discrepancy between computed and experimental bond lengths available for $[\mathbf{R u} b p y]^{2+3 b}$ and $[\mathbf{R u}$ $\mathrm{dcbpy}]^{2+3 b}$ is $\sim 0.01 \AA$ for $\mathrm{Ru}-\mathrm{N}$ bonds and $0.02 \AA$ for $\mathrm{Ru}-\mathrm{S}$ bonds. The introduction of bulky substituents on the bidentate ligand provokes an elongation of $\mathrm{Ru}-\mathrm{N} 4$ and $\mathrm{Ru}-\mathrm{N} 5$ bond lengths by $0.04-0.06 \AA$, which is in the range of previously reported values for related 
complexes. $^{2 \mathrm{a}, 20}$ At this stage, it is thus impossible to differentiate the three N-N ligands in terms of geometrical parameters.

Table 1. Selected bond lengths $(\AA)$ and angles $(\mathrm{deg})$ for the ground state and for the lowest triplet states ${ }^{\mathrm{a}}$

\begin{tabular}{|c|c|c|c|c|c|}
\hline & $\mathrm{Ru}-\mathrm{S}$ & Ru-N5 & S-Ru-N5 & $\mathrm{Ru}-\mathrm{N} 5-\mathrm{C} 4-\mathrm{C} 3$ & S-Ru-N4-C3 \\
\hline \multicolumn{6}{|c|}{$[\mathbf{R u} \text { bpy }]^{2+}$} \\
\hline${ }^{1} \mathrm{GS}$ & $2.370(2.369)^{b}$ & $2.050(2.064)^{b}$ & 171.3 & $0.4(2.3)^{b}$ & 178.9 \\
\hline${ }^{3} \mathrm{MLCT}$ & 2.374 & 2.061 & 174.2 & 2.4 & 178.6 \\
\hline${ }^{3} \mathrm{MC}_{\text {hexa }}$ & 3.081 & 2.382 & 169.2 & 0 & 178.9 \\
\hline \multicolumn{6}{|c|}{$[\mathrm{Ru} \text { biq }]^{2+}$} \\
\hline${ }^{1} \mathrm{GS}$ & 2.381 & 2.090 & 166.4 & 26.6 & 145.3 \\
\hline${ }^{3} \mathrm{MLCT}$ & 2.407 & 2.012 & 168.5 & 21.8 & 143.5 \\
\hline${ }^{3} \mathrm{MC}_{\text {hexa }}$ & 2.782 & 2.388 & 156.3 & 35.7 & 139.6 \\
\hline${ }^{3} \mathrm{MC}_{\text {penta }}{ }^{\mathrm{c}}$ & 3.803 & 2.300 & 151.4 & 10.7 & 147.0 \\
\hline \multicolumn{6}{|c|}{$[\mathbf{R u} \text { dcbpy }]^{2+}$} \\
\hline${ }^{1} \mathrm{GS}$ & $2.378(2.382)^{b}$ & $2.110(2.115)^{b}$ & 167.5 & $25.8(22.0)^{b}$ & 145.5 \\
\hline${ }^{3} \mathrm{MLCT}$ & 2.369 & 2.168 & 170.0 & 25.6 & 147.6 \\
\hline${ }^{3} \mathrm{MC}_{\text {hexa }}$ & 2.940 & 2.505 & 154.7 & 34.8 & 138.5 \\
\hline${ }^{3} \mathrm{MC}_{\text {penta }}{ }^{c}$ & 3.813 & 2.350 & 156.9 & 5.1 & 151.8 \\
\hline \multicolumn{6}{|c|}{$[\mathbf{R u} \text { dmbpy }]^{2+}$} \\
\hline${ }^{1} \mathrm{GS}$ & 2.380 & 2.103 & 167.1 & 24.3 & 145.5 \\
\hline${ }^{3} \mathrm{MLCT}$ & 2.391 & 2.121 & 170.4 & 20.0 & 146.9 \\
\hline${ }^{3} \mathrm{MC}_{\text {penta }}{ }^{c}$ & 3.923 & 2.312 & 154.2 & 8.2 & 149.4 \\
\hline
\end{tabular}

${ }^{\mathrm{a}} \mathrm{N} 5$ is located trans to the thioether ligand. ${ }^{\mathrm{b}}$ Single-crystal X-ray data are provided in parentheses for [Ru bpy] ${ }^{2+}$

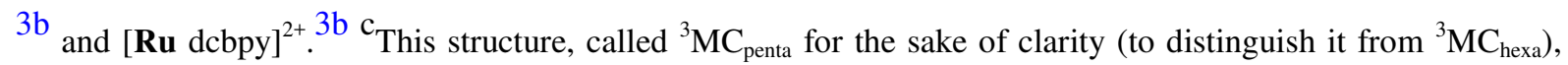
can be viewed as a weakly bound complex.

The molecular orbital (MO) diagrams that characterize the electronic structures of the four complexes in their ground state are reported in Figure 2. For all of the complexes, the three highest occupied molecular orbitals (HOMOs) are metallic d orbitals with minor contributions of the ligands, while the lowest unoccupied molecular orbitals (LUMOs) are the $\pi^{*}$ orbitals of the polypyridyl ligand (tpy, N-N, or both). It is noteworthy that the localization of the LUMO reflects the $\pi$-accepting properties of the bidentate ligand. For [Ru bpy] $]^{2+}$ the LUMO is only located on the tpy ligand and for $[\mathbf{R u} \text { dcbpy }]^{2+}$ and $[\mathbf{R u} \mathrm{dmbpy}]^{2+}$ the LUMO is distributed on both polypyridyl ligands; the LUMO of $[\mathbf{R u} \text { biq }]^{2+}$ mainly resides on the biquinoline ligand. The large delocalized $\pi$ system of the biq ligand is responsible for the intercalation of a lowlying $\pi^{*}$ energy level, which significantly decreases the HOMO-LUMO energy gap in comparison to the other complexes. Higher in the diagram, metal-centered vacant MOs $\left(\mathrm{d} \sigma^{*}\right)$ show $\sigma$-antibond- ing interactions between the d orbital of the metal and the S and N5 atoms. ${ }^{3} \mathrm{MC}$ states are the result of the occupation of these antibonding orbitals. ${ }^{21}$

Adding substituents at the bpy ligand lowers the $d \sigma^{*}$ energy, confirming the influence of 
steric effects on the ligand field. This effect is tempered in the case of $[\mathbf{R u} \mathrm{dmbpy}]^{2+}$ by the $\sigma$ donor effects of the methyl group, which provoke a slight destabilization of this antibonding orbital.

As for the geometrical parameters, dcbpy and dmbpy induce very similar electronic effects.

Figure 2. Ground state MO diagrams illustrating the electronic structure of the investigated complexes. Energy levels related to metallic orbitals are displayed as solid lines, and those of ligand-based orbitals are shown as dashed lines. Only frontier MOs are drawn for clarity. The HOMO energy is set to 0 .

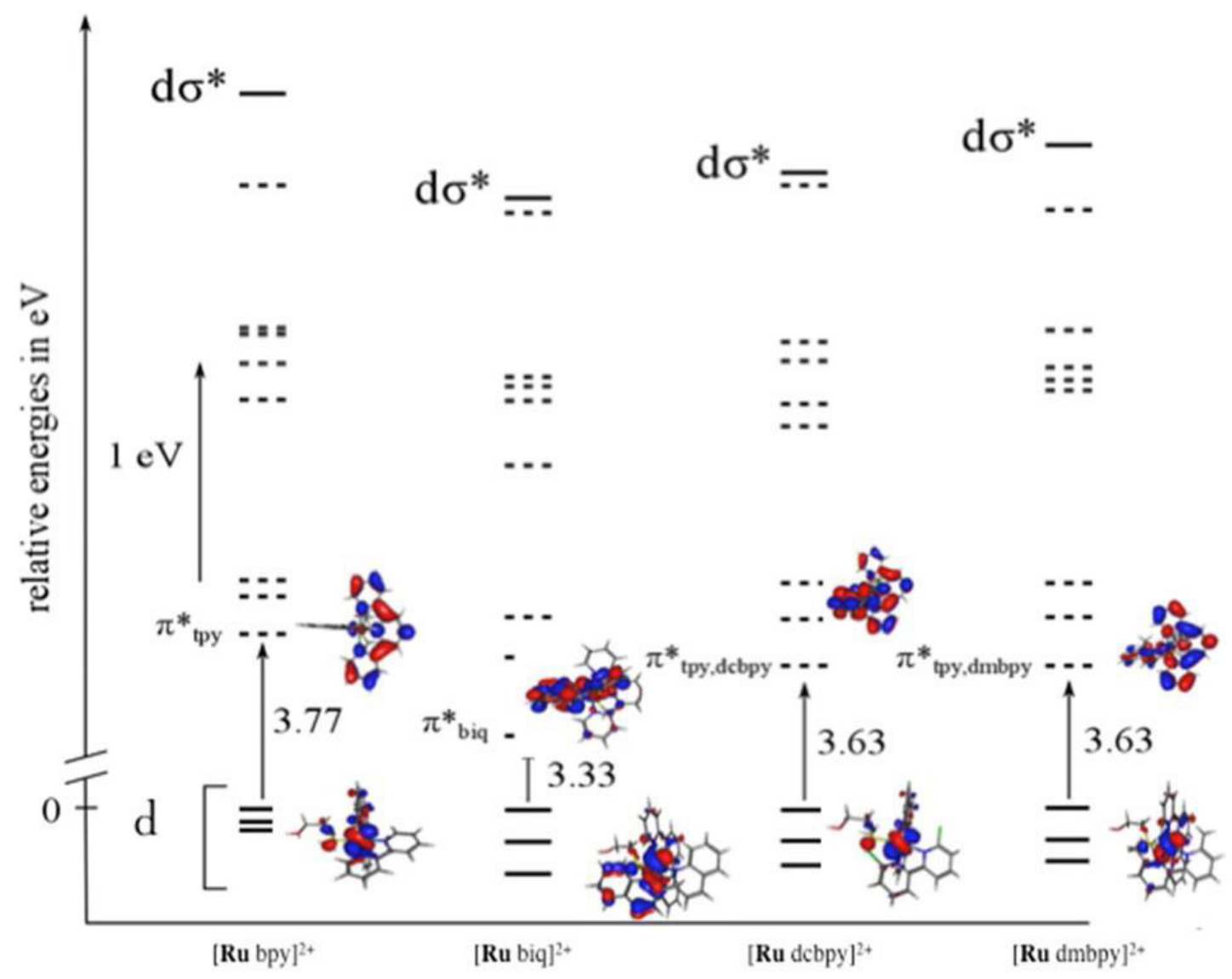

Singlet Metal-to-Ligand Charge-Transfer state ( ${ }^{1}$ MLCT). As is well admitted now, the photoexcitation process begins by the population of a set of singlet metal to ligand charge transfer states ( ${ }^{1}$ MLCT). Then, intersystem crossing (ISC) takes the complexes to their triplet metal to ligand charge transfer states $\left({ }^{3} \mathrm{MLCT}\right)$, which can either return to the ground state by radiative deactivation or be trapped by the nonradiative triplet metal-centered state $\left({ }^{3} \mathrm{MC}\right)$. The latter are responsible for the photoreactivity of these complexes.

TD-DFT calculations were performed to identify possible candidates for the first step of the photochemical cascade. Only the part of the spectrum ranging from 250 to $550 \mathrm{~nm}$ was 
investigated, which corresponds to the experimental window showing large absorption bands: i.e., $\lambda_{\max } 450 \mathrm{~nm}\left([\mathbf{R u} \text { bpy }]^{2+}\right), 463 \mathrm{~nm}\left([\mathbf{R u} \mathrm{dmbpy}]^{2+}\right), 467 \mathrm{~nm}\left([\mathbf{R u} \mathrm{dcbpy}]^{2+}\right)$, and $519 \mathrm{~nm}$ $\left([\mathbf{R u} \text { biq }]^{2+}\right)$. The computed absorption spectra in this wavelength range are reported on Figure 3. The envelopes of each simulated spectrum feature several maxima, but one can clearly distinguish a band with higher intensity. This maximum is respectively located at 400 $\left([\mathbf{R u ~ b p y}]^{2+}\right), 410\left([\mathbf{R u} \mathrm{dmbpy}]^{2+}\right), 430\left([\mathbf{R u} \mathrm{dcbpy}]^{2+}\right)$, and $482 \mathrm{~nm}\left([\mathbf{R u} \text { biq }]^{2+}\right)$, which gives a discrepancy with experiment within the accepted margin of error for such TD-DFT calculations (ca. $0.3 \mathrm{eV}$ ).

Figure 3. Simulated absorption spectra of the four complexes. Theoretical and experimental values of the absorption maxima are indicated in nanometers for comparison $\left(\lambda_{\text {theor }} / \lambda_{\text {exp }}\right)$.

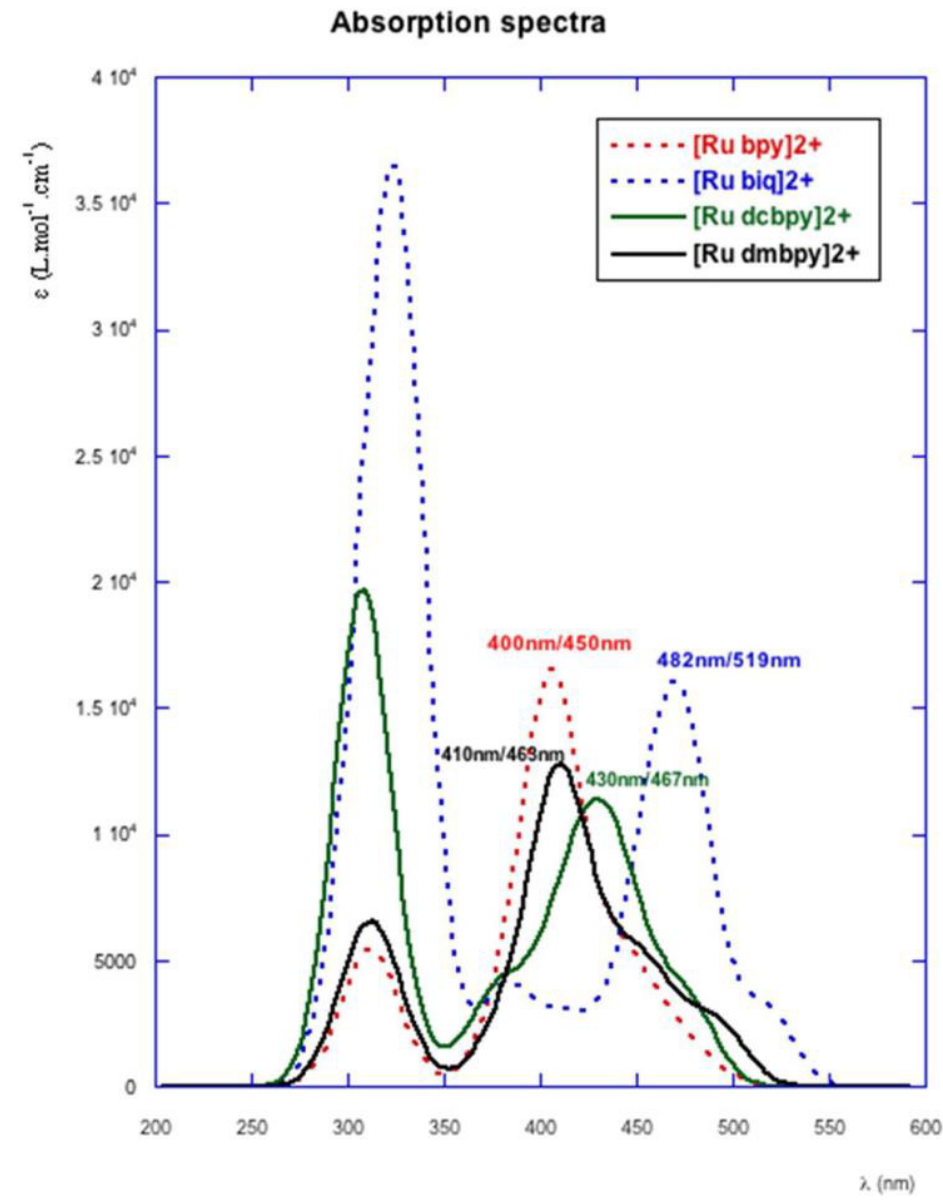

According to TD-DFT calculations all transitions are of MLCT nature, since they are described by monoexcitations from $d$ orbitals to the $\pi^{*}$ virtual orbitals. Below $350 \mathrm{~nm}$, the highest strong energy bands are MLCT transitions from Ru (4d) orbitals to $\pi^{*}$ orbitals of tpy and bpy ligands. Following the replacement of bpy by dmbpy, dcbpy, and biq, the calculated maximum of the absorption band, mirroring the trend in experimental UV-visible absorption 
data, is progressively red shifted due to the stabilization of the LUMO. This stabilization is far more significant for the $[\mathbf{R u} \text { biq }]^{2+}$ complex as a consequence of the population of the lowenergy $\pi^{*}$ orbital of the biquinoline ligand (Figure 2).

Lowest triplet potential energy surface. To discuss emissive properties and to unveil the ligand substitution mechanisms, we explored for each complex its lowest ${ }^{3} \mathrm{PES}$. With the protocol used in previous studies ${ }^{13,22}$ and recalled in Computational Methods, we were able to obtain :

(i) optimized geometries of different triplet state minima, with one ${ }^{3} \mathrm{MLCT}$ and one ${ }^{3} \mathrm{MC}$ in the case of $[\mathbf{R u} \text { bpy }]^{2+}$ and $[\mathbf{R u} d m b p y]^{2+}$ and with one ${ }^{3}$ MLCT and two ${ }^{3} \mathrm{MCs}$ in the case of $[\mathbf{R u} \text { biq }]^{2+}$ and $[\mathbf{R u} \text { dcbpy }]^{2+}$

(ii) two different types of connecting points: i.e., TSs between ${ }^{3} \mathrm{MLCT} /{ }^{3} \mathrm{MC}$ and MECPs between ${ }^{3} \mathrm{MC}$ and ${ }^{1} \mathrm{GS}$.

The geometries of the stationary points and their relative free energies are reported in Tables 1 and 3, respectively. Figure 4 represents the free energy pathway connecting ${ }^{3}$ MLCT and ${ }^{3} \mathrm{MC}$ states for the four complexes.

Figure 4. Schematic representation of the free energy profiles computed with DFT in water at $298 \mathrm{~K}$ for [Ru bpy $]^{2+}$ (in red), $[\mathbf{R u} \text { biq }]^{2+}$ (in blue), $[\mathbf{R u} \text { dmbpy }]^{2+}$ (in black), and $[\mathbf{R u} \text { dcbpy }]^{2+}$ (in green). The ${ }^{3}$ MLCT states were deliberately placed at the same origin for clarity.

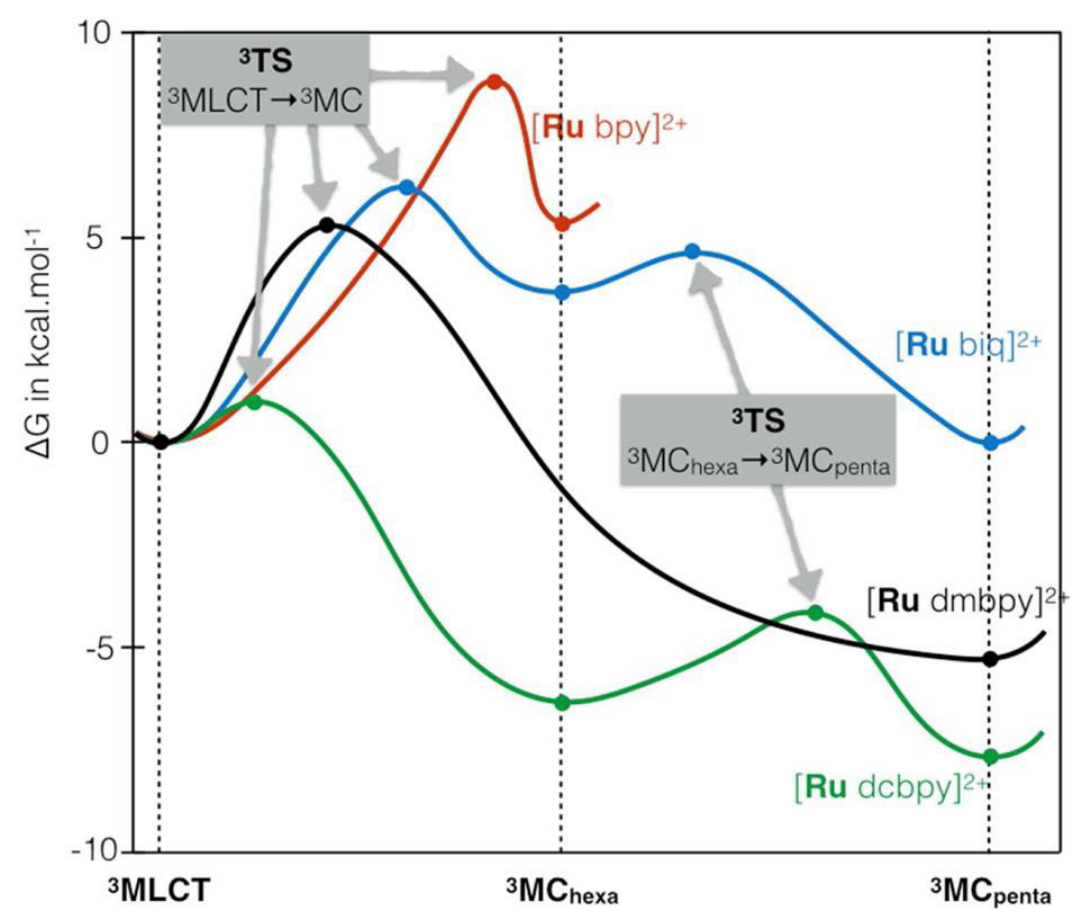


${ }^{3}$ MLCT states. The geometries of the lowest MLCT states for the four complexes closely resemble those of their respective GS geometry. In the four species, the SOMO-1, namely the hole, is essentially localized on the Ru atom, while the SOMO, namely the electron, is localized on tpy for $[\mathbf{R u} b p y]^{2+},[\mathbf{R} \mathbf{u} \mathrm{dmbpy}]^{2+}$, and $[\mathbf{R u} \text { dcbpy }]^{2+}$ and on biq in $[\mathbf{R u} \text { biq }]^{2+}$, as could be predicted from the orbital ordering of the ground state (Figure 2).

${ }^{3} M C$ states. The commonly accepted model for the photophysical cascade resulting in ligand dissociation ends by the population of a potentially reactive ${ }^{3} \mathrm{MC}$ state. ${ }^{2 \mathrm{c}}$ For two complexes we found that two distinct ${ }^{3} \mathrm{MC}$ minima are able to play a major role in ligand photocleavage. It is noteworthy that both structures correspond to the same electronic state.

These two optimized ${ }^{3} \mathrm{MC}$ geometries result from the same excitation of a $\mathrm{Ru}(4 \mathrm{~d})$ electron to a $\mathrm{d}^{*} \mathrm{MO}$ that is antibonding between the metal and the departing Hmte ligand and the nitrogen atom in a trans position (N5). A closer look at the geometries of these optimized ${ }^{3} \mathrm{MC}$ states, displayed in Tables 1 and 3, reveals that two different structural isomers of the ${ }^{3} \mathrm{MC}$ state have been characterized, sharing the same electronic occupancy. The first isomer, referred to as ${ }^{3} \mathrm{MC}_{\mathrm{hexa}}$, is characterized by a geometry where the $\mathrm{Ru}-\mathrm{S}$ bond elongates to ca. $2.9 \AA$ while the $\mathrm{Ru}-\mathrm{N} 5$ elongates to ca. $2.4 \AA$. A slight distortion evidenced by the angle between the mean planes of the tpy and N-N ligands is still present with respect to GS, as shown in Table 2 . This ${ }^{3} \mathrm{MC}_{\text {hexa }}$ state has been characterized for $[\mathbf{R u} b p y]^{2+},[\mathbf{R u} \text { biq }]^{2+}$, and $[\mathbf{R u} \text { dcbpy }]^{2+}$ but not for [Ru dmbpy $]^{2+}$. The second isomer, referred to as ${ }^{3} \mathrm{MC}_{\text {penta }}$, ${ }^{2 \mathrm{e}}$ exhibits a much longer $\mathrm{Ru}-\mathrm{S}$ distance, up to $4 \AA$, accompanied by a shortening of the trans $\mathrm{Ru}-\mathrm{N} 5$ bond and by a planarization of the bidentate ligand, as testified by the values of mean plane angles which increase to reach $85.7^{\circ}$ in the case of $[\mathbf{R u} \text { dcbpy }]^{2+}$. These rearrangements clearly design these ${ }^{3} \mathrm{MC}_{\text {penta }}$ states as ideal starting structures for the photoinduced Hmte departure. Similar structures have been previously proposed for the photorelease of a pyridine ligand. ${ }^{2 \mathrm{j}}$ These ${ }^{3} \mathrm{MC}_{\mathrm{penta}}$ states were found for $[\mathbf{R u} \mathrm{biq}]^{2+},[\mathbf{R} \mathbf{u} \mathrm{dcbpy}]^{2+}$, and $[\mathbf{R u} \mathrm{dmbpy}]^{2+}$ but not for $[\mathbf{R u} b p y]^{2+}$. From an energetic point of view, the binding energy was calculated between the metallic moiety $[\mathrm{Ru}(\operatorname{tpy})(\mathrm{N}-\mathrm{N})]^{2+}$ and the Hmte ligand corrected for intramolecular basis set superposition error. ${ }^{23}$ The Hmte ligand interacts with the rest of the complex more strongly in the ${ }^{3} \mathrm{MC}_{\text {hexa }}$ state (mean value of ca. $12 \mathrm{kcal} \mathrm{mol}^{-1}$ ) than in the ${ }^{3} \mathrm{MC}_{\text {penta }}$ (mean value of ca. $7 \mathrm{kcal} \mathrm{mol}{ }^{-1}$ ). Photorelease of the monodentate ligand is thus facilitated in the ${ }^{3} \mathrm{MC}_{\text {penta }}$ state. As detailed later, the existence and population of the ${ }^{3} \mathrm{MC}_{\text {penta }}$ state clearly facilitates photocleavage. 
Table 2. Comparative views of the GS, ${ }^{3} \mathrm{MC}_{\mathrm{hexa}}$, and ${ }^{3} \mathrm{MC}_{\mathrm{penta}}$ states of $[\mathrm{Ru}(\mathrm{tpy})(\mathrm{N}-\mathrm{N})(\mathrm{Hmte})]^{2+}$ complexes along the N2-Ru axis ${ }^{\mathrm{a}}$

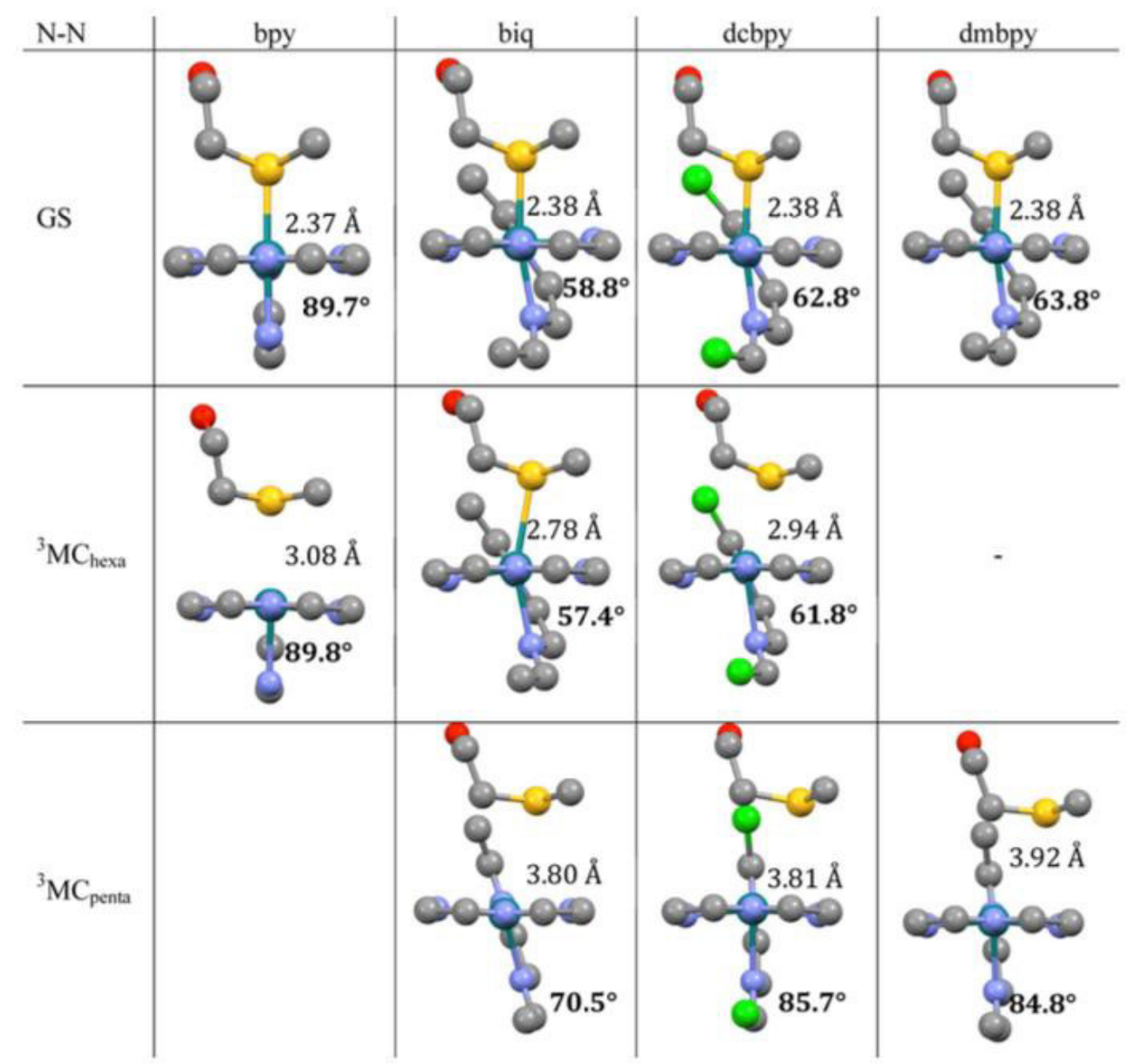

${ }^{\mathrm{a}}$ Some atoms are hidden for clarity. Values indicate the $\mathrm{Ru}-\mathrm{S}$ bond distance and the angle (in boldface) between the mean planes of tpy (horizontal) and the bidentate ligand (more or less vertical).

Connecting points. For the four complexes, the geometries of the TS between the ${ }^{3}$ MLCT and ${ }^{3} \mathrm{MC}$ states $\left(\mathrm{TS}-{ }^{3} \mathrm{MLCT} /{ }^{3} \mathrm{MC}\right.$ ) were optimized, as well as that of the MECPs along the photodeactivation coordinate (MECP- ${ }^{3} \mathrm{MC} /{ }^{1} \mathrm{GS}$, denoted $\left.{ }^{1 / 3} \mathrm{MECP}\right)$. Geometries, electronic structures, and energetic data of these states are detailed in Tables S6, S9, S13, and S19-S22. The four TSs connecting the ${ }^{3} \mathrm{MLCT}$ and the ${ }^{3} \mathrm{MC}$ minima are easily accessible from the ${ }^{3}$ MLCT state, since the highest Gibbs activation energy was found to be $8.8 \mathrm{kcal} \mathrm{mol}^{-1}$ (for the bpy ligand). The $\mathrm{Ru}-\mathrm{S}$ bond initiates its elongation, up to $0.4 \AA$, in these TS structures. The spin density on ruthenium in the TS states has values intermediate between the usual ones expected for a ${ }^{3} \mathrm{MLCT}$ state $(\sim 0.8)$ and a ${ }^{3} \mathrm{MC}$ state $(\sim 1.8)$. Note that both the $\mathrm{Ru}-\mathrm{S}$ elongation and the spin density values are consistent with the Hammond postulate. ${ }^{24}$ Large $\mathrm{Ru}-\mathrm{S}$ elongation $(0.402 \AA)$ and high spin density (1.30) are consistent with the endergonic 
profile of $[\mathbf{R u} b p y]^{2+}$. In contrast, a small $\mathrm{Ru}-\mathrm{S}$ elongation $(0.128 \AA)$ and a lower spin density on ruthenium of the $[\mathbf{R u} \text { dcbpy }]^{2+}$ complex (1.16) are consistent with the most exergonic profile of the series. These particular geometries are the key points upon which we will build our description of the photorelease of the Hmte ligand.

Table 3.

\begin{tabular}{lcccc}
\multicolumn{5}{c}{$\mathrm{N}-\mathrm{N}$} \\
\hline & bpy & biq & dcbpy & dmbpy \\
\hline$\Delta G\left({ }^{3} \mathrm{MLCT} \rightarrow{ }^{3} \mathrm{MC}_{\text {hexa }}\right)^{a}$ & +5.3 & +3.7 & -5.9 & -5.2 \\
$\Delta G\left({ }^{3} \mathrm{MLCT} \rightarrow{ }^{3} \mathrm{MC}_{\text {penta }}\right)^{a}$ & & 0.0 & -7.6 & -42 \\
$\Delta G\left({ }^{3} \mathrm{MLCT} \rightarrow \mathrm{GS}\right)^{a}$ & -43 & -36 & -44 & 5.3 \\
$\Delta G^{\ddagger}\left({ }^{3} \mathrm{MLCT} \rightarrow{ }^{3} \mathrm{TS}\right)$ & 8.8 & 6.2 & 1 & $+39 /-$ \\
$\Delta E\left(\mathrm{GS} \rightarrow{ }^{3} \mathrm{MC} \mathrm{C}_{\text {hexa }}\right) / \Delta E\left(\mathrm{GS} \rightarrow{ }^{3} \mathrm{MC}_{\text {penta }}\right)^{b}$ & $+50 /-$ & $+43.5 /+40.5$ & $+38.9 /+38.9$ & 0.30 \\
$\varphi$ at $297 \mathrm{~K}^{c}$ & 0.022 & 0.12 & 0.13 &
\end{tabular}

${ }^{\text {a }}$ Relative Gibbs energy (in $\mathrm{kcal} \mathrm{mol}^{-1}$ ) of the stationary points involved along the photodissociation profiles calculated in water using COSMO with ${ }^{3} \mathrm{MLCT}$ states as reference. ${ }^{\mathrm{b}}$ Energy difference between ${ }^{3} \mathrm{MC}$ states and ground states. ${ }^{c}$ Experimental photosubstitution quantum yield of $[\mathrm{Ru}(\mathrm{tpy})(\mathrm{N}-\mathrm{N})(\mathrm{Hmte})]^{2+}$ in water according to ref $3 b$.

Theoretical mechanistic scheme. A schematic, but realistic, overall energy profile for the photosubstitution process is shown in Figure 5. In this sketch we adopt the terminology proposed by Morokuma et al. ${ }^{2 \mathrm{~d}}$ To formalize the change in reaction coordinate together with the chemical system during the photosubstitution process, we distinguish three areas: i.e., different reaction coordinates are successively followed along this profile. In the first area, called the "transition process", the process is initiated; it is the MLCT state domain. The second area is where the photocleavage step occurs; it is the region of the ${ }^{3} \mathrm{MC}$ states. The last area (out of the scope of this work) terminates the process by forming the aqua product. Upon irradiation, the population of the ${ }^{1}$ MLCT manifold occurs, followed by ultrafast ICs and ISCs that lead to the population of ${ }^{3}$ MLCT states on the lowest ${ }^{3} \mathrm{PES}$. From there, overcoming the TS $-{ }^{3} \mathrm{MLCT} /{ }^{3} \mathrm{MC}$ state allows the complex to access the ${ }^{3} \mathrm{MC}$ region, where the departure of the Hmte ligand can occur. Similarly, a vast ${ }^{3} \mathrm{MC}$ region had been identified in Ru sulfoxide complexes, in that case leading to linkage isomerization. ${ }^{22 a, b}$

From our results, three situations can be distinguished that illustrate the different behaviors of the different complexes. They are schematized in Figure 5 by inserts (a)-(c).

Figure 5. Schematic potential energy profiles including the lowest energy states involved in the proposed decoordination pathway. Red dots refer to optimized geometries (minima, TS, MECP). The transition process 
area refers to the relaxation processes leading to the population of ${ }^{3} \mathrm{MC}$ states, the Hmte dissociation area refers to the adiabatic reaction pathway leading to the dissociation of the Hmte ligand, and the final water recoordination region is a hypothetical proposition of nonadiabatic reactivity supporting the formation of the aqua complexes.

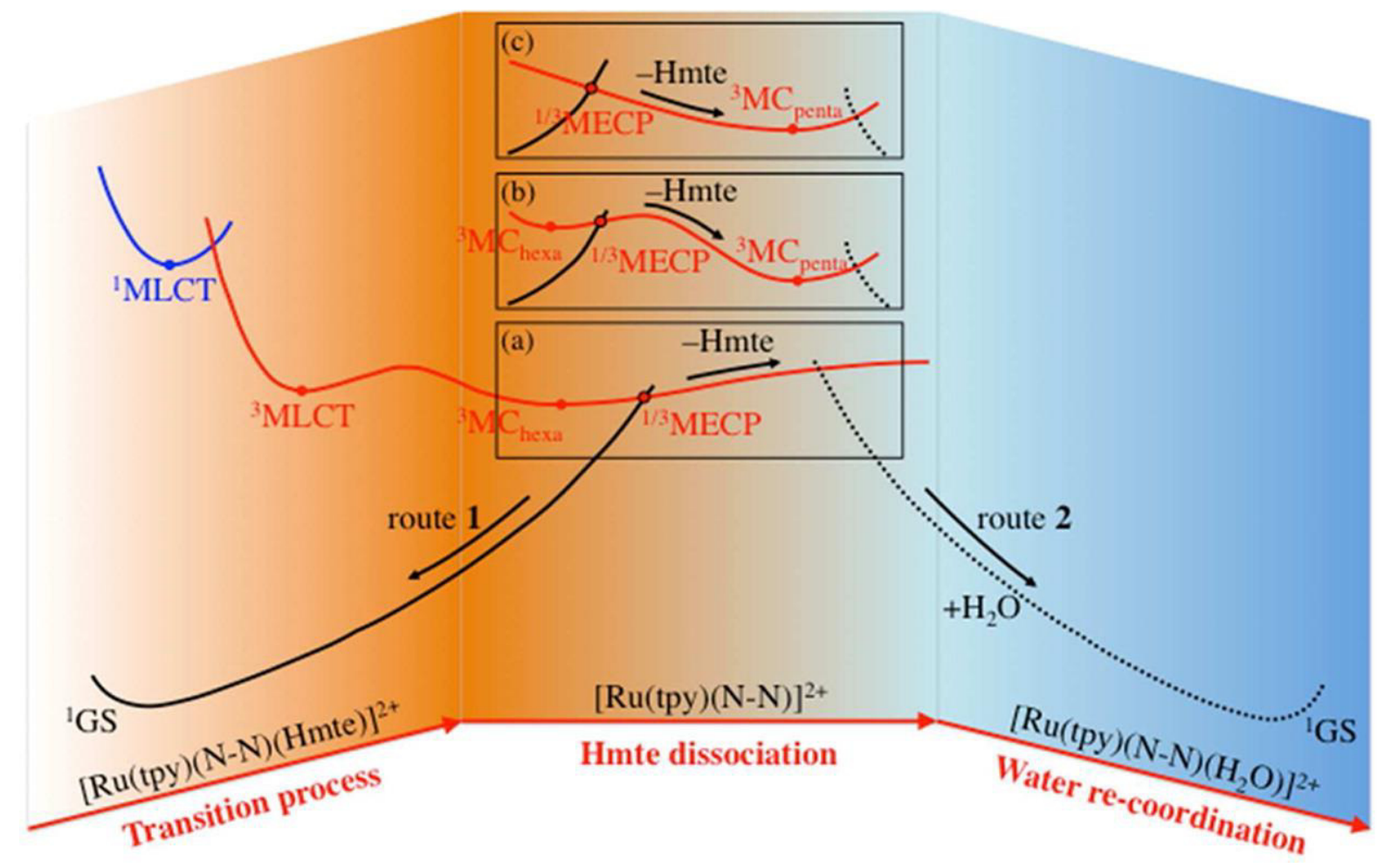

Insert (a): from the ${ }^{3} \mathrm{MC}_{\text {hexa }}$ state, the ${ }^{1 / 3} \mathrm{MECP}$ is easily accessible; the system will be able to surmount this minor barrier and will relax to the ground state by nonradiative decay and without ligand substitution (route 1). The proximity and accessibility of the ${ }^{1 / 3} \mathrm{MECP}$ structure from the ${ }^{3} \mathrm{MC}_{\text {hexa }}$ minimum guarantees a high photostability for these complexes: i.e., low photosubstitution quantum yields.

Insert (b): the coexistence of two minima $\left({ }^{3} \mathrm{MC}_{\text {hexa }}\right.$ and $\left.{ }^{3} \mathrm{MC}_{\text {penta }}\right)$ on the flat ${ }^{3} \mathrm{MC}$ surface opens two competing pathways. In addition to the possibility of following route 1 and restoring the initial complex, the ${ }^{3} \mathrm{MC}_{\text {penta }}$ state can be easily reached from the ${ }^{3} \mathrm{MC}_{\text {hexa }}$ state. Indeed, the resemblance of the ${ }^{3} \mathrm{MC}_{\text {hexa }}$ and ${ }^{3} \mathrm{MC}_{\text {penta }}$ reflected in the very close energies between these two MC states results in a very small activation barrier: ca. $1.8 \mathrm{kcal} \mathrm{mol}-1$ for $[\mathbf{R u} \mathrm{dcbpy}]^{2+}$ and $1 \mathrm{kcal} \mathrm{mol}^{-1}$ for $[\mathbf{R u} \mathrm{biq}]^{2+}$. Minimum energy paths (MEP) are displayed in Figures S1 and S2 in the Supporting Information. The coordination of a water molecule is not addressed in this study, but our hypothesis is that the ${ }^{3} \mathrm{MC}_{\text {penta }}$ could cross the ground state PES of the aqua product, enabling solvent substitution to yield $[\mathrm{Ru}(\mathrm{tpy})(\mathrm{N}-\mathrm{N})(\mathrm{H} 2 \mathrm{O})]^{2+}$ (route 2 in Figure 5) or to undergo diffusional separation. ${ }^{2 \mathrm{e}}$ Both routes are kinetically and 
thermodynamically competitive, leading to ruthenium complexes of intermediate photostability and intermediate photosubstitution quantum yields.

Insert (c): Direct population of the ${ }^{3} \mathrm{MC}_{\text {penta }}$ state by interconversion from the ${ }^{3} \mathrm{MLCT}$ state, which is a consequence of the absence of a ${ }^{3} \mathrm{MC}_{\text {hexa }}$ local minimum, favors route 2 with relaxation of the ${ }^{3} \mathrm{MC}_{\text {penta }}$ to the ground state of the aqua complex or to diffusional separation. $^{2 \mathrm{e}}$ These complexes are ideal for ligand solvolysis and will show high photosubstitution quantum yields.

In the following discussion we confirm the well-accepted model where the accessibility and the population of a ${ }^{3} \mathrm{MC}$ state is a key factor to achieve photoinduced ligand exchange. From Figure 4, we can see that the ${ }^{3} \mathrm{MC}$ states $\left(\mathrm{MC}_{\text {hexa }}\right.$ and/or $\left.\mathrm{MC}_{\text {penta }}\right)$ for $[\mathbf{R u} \text { biq }]^{2+}$, $[\mathbf{R u} \text { dcbpy }]^{2+}$, and $[\mathbf{R u ~ d m b p y}]^{2+}$ are lower in energy than the corresponding ${ }^{3}$ MLCT states, consistent with the absence of luminescence for these three species. [Ru bpy] ${ }^{2+}$ has its ${ }^{3} \mathrm{MC}_{\text {hexa }}$ state above its ${ }^{3}$ MLCT state, and these two states are separated by the largest free activation energy barrier $\left(8.8 \mathrm{kcal} \mathrm{mol}^{-1}\right)$. A small backward activation free energy barrier will favor the ${ }^{3} \mathrm{MC}_{\text {hexa }} \rightarrow$ ${ }^{3}$ MLCT back-conversion. Such results are consistent with experimental observations indicating that $[\mathbf{R u} b p y]^{2+}$ is the only complex of the series which displays a weak luminescence at $298 \mathrm{~K}$ (see Figure S3 in the Supporting Information). The vertical emission energy calculated from the ${ }^{3}$ MLCT state is in excellent agreement $(630 \mathrm{~nm})$ with the experimental emission wavelength $(650 \mathrm{~nm}$; see Figure S3). As illustrated in insert (a), our calculations on the lowest ${ }^{3} \mathrm{PES}$ of $\left[\mathbf{R u}\right.$ bpy ${ }^{2+}$ located only one ${ }^{3} \mathrm{MC}$ minimum. Close to this state, we have identified a highly accessible crossing point, ${ }^{1 / 3} \mathrm{MECP}$, located only $2.8 \mathrm{kcal}$ $\mathrm{mol}^{-1}$ above the ${ }^{3} \mathrm{MC}_{\text {hexa }}$ minimum. The accessibility of this $\mathrm{MECP}$, which provides a facile pathway back to the ground state, combined with the absence of ${ }^{3} \mathrm{MC}_{\text {penta }}$, prevents efficient photoreactions from occurring and explains the small experimental value found for the quantum yield of photo- substitution of the Hmte ligand by a water molecule $(\varphi=0.022){ }^{3 b}$ According to our analysis, the best schematic picture explaining the behavior of $[\mathbf{R u} b p y]^{2+}$ is that described by insert (a).

For $\left[\mathbf{R u}\right.$ dmbpy] ${ }^{2+}$ the ${ }^{3}$ MLCT state must overcome a small barrier of $5.3 \mathrm{kcal} \mathrm{mol}^{-1}$ to directly reach a ${ }^{3} \mathrm{MC}_{\text {penta }}$ state, which is computed to be $5.2 \mathrm{kcal} \mathrm{mol}^{-1}$ lower in energy than the ${ }^{3} \mathrm{MLCT}$ state. Once this ${ }^{3} \mathrm{MC}_{\text {penta }}$ state is populated, the nearby crossing point ${ }^{1 / 3} \mathrm{MECP}$ is easily accessible $\left(0.9 \mathrm{kcal} \mathrm{mol}^{-1}\right)$, that allows the system to deactivate into the ground state. However, in this case the highly elongated $\mathrm{Ru}-\mathrm{S}$ distance observed in the ${ }^{3} \mathrm{MC}_{\text {penta }}$ state suggests a $\mathrm{Ru}-\mathrm{S}$ bond cleavage pathway following a quasi-dissociative mechanism. Meanwhile, the absence of an energy barrier on the flat landscape of the ${ }^{3} \mathrm{PES}$ must facilitate 
the decoordination of the ligand, which fits with the highest observed photosubstitution quantum yield in the series $(\varphi=0.30)$. Thus, according to this analysis, insert (c) best describes the photochemical behavior of $[\mathbf{R u} \mathrm{dmbpy}]^{2+}$. It is noteworthy that, to ensure the absence of ${ }^{3} \mathrm{MC}_{\text {hexa }}$ geometry as a minimum in the case of the dmbpy ligand, we tried to reach the ${ }^{3} \mathrm{MC}_{\text {hexa }}$ isomer by starting a geometry optimization from the ${ }^{3} \mathrm{MC}_{\text {hexa }}$ state of the [Ru $\mathrm{dcbpy}]^{2+}$ complex, replacing the chloride atoms by methyl groups. No true minimum was found, however: i.e., [Ru dmbpy ${ }^{2+}$ only displays the ${ }^{3} \mathrm{MCpenta}$ isomer.

Finally, $[\mathbf{R u} \text { dcbpy }]^{2+}$ and $[\mathbf{R u} \text { biq }]^{2+}$ behave similarly. For both complexes we were able to distinguish two local minima on the excited ${ }^{3} \mathrm{PES},{ }^{3} \mathrm{MC}_{\text {hexa }}$ and ${ }^{3} \mathrm{MC}_{\text {penta }}$, with the ${ }^{3} \mathrm{MC}_{\text {penta }}$ isomer being more stable than the usual ${ }^{3} \mathrm{MC}_{\text {hexa }}$ isomer and with only a small barrier between these two structures. In our analysis the intermediate photostability measured for these two complexes is best illustrated by insert (b). Indeed, the population of the ${ }^{3} \mathrm{MC}_{\text {hexa }}$ state may either lead to repopulation of GS via the ${ }^{1 / 3} \mathrm{MECP}$ (almost degenerate with ${ }^{3} \mathrm{MC}_{\text {hexa }}$, i.e., located at 0.3 and $0.9 \mathrm{kcal} \mathrm{mol}^{-1}$ ) following route 1 or undergo ligand substitution via the ${ }^{3} \mathrm{MC}_{\mathrm{penta}}$ isomer (route 2) to form the aqua photoproducts $\left[\mathrm{Ru}(\mathrm{tpy})(\mathrm{biq})\left(\mathrm{H}_{2} \mathrm{O}\right)\right]^{2+}$ and $\left[\mathrm{Ru}(\mathrm{tpy})(\mathrm{dcbpy})\left(\mathrm{H}_{2} \mathrm{O}\right)\right]^{2+}$. These two competitive processes explain in part the intermediate values of 0.12 and 0.13 found experimentally for the photosubstitution quantum yields of [Ru biq $]^{2+}$ and $[\mathbf{R u} \text { dcbpy }]^{2+}$, respectively.

Comparison to experimental data. Qualitatively, our calculations confirm the usual arguments explaining the effect of the distorted geometry of this family of complexes on the ligand field splitting energy, which in turn stabilizes the $d \sigma^{*}$ orbitals and consequently renders the ${ }^{3} \mathrm{MC}$ states more accessible from the photochemically generated ${ }^{3} \mathrm{MLCT}$ states. A quick look at the GS $d \sigma^{*}$ orbital relative energy displayed in Figure 2 and ${ }^{3} \mathrm{MLCT} /{ }^{3} \mathrm{MC}_{\text {hexa }}$ or ${ }^{3} \mathrm{MLCT} /{ }^{3} \mathrm{MC}_{\text {penta }}$ energy gaps seems to match perfectly the experimental values for the photosubstitution quantum yields. Indeed, relative to $[\mathbf{R u} b p y]^{2+}$, the three hindered complexes $[\mathbf{R u} \text { biq }]^{2+}$, [Ru dcbpy $]^{2+}$, and $[\mathbf{R u} \mathrm{dmbpy}]^{2+}$ show more distorted GS geometries and lower energies for their reactive ${ }^{3} \mathrm{MC}$ states, which is consistent with the higher experimental photo- substitution quantum yields in water.

However, in a more refined discussion, distorted geometries, as well as electronic and steric effects of the substituents on the bidentate ligand, are insufficient to explain the difference in photosubstitution quantum efficiency between $[\mathbf{R u} \text { biq }]^{2+}$ and $[\mathbf{R u} \mathrm{dcbpy}]^{2+}$ on the one hand and $[\mathbf{R u} \mathrm{dmbpy}]^{2+}$ on the other hand. Previous works of Takeuchi ${ }^{25}$ on similar molecules and 
of Charton ${ }^{26}$ on the measurement of steric effects concerning chlorine and methyl substituents do not allow distinguishing this effect in the three hindered complexes. None of the computed factors, i.e., neither the angle between the mean planes of tpy and the bidentate ligand nor the GS $/^{3} \mathrm{MC}$ energy gap values (Table 3), are different enough to contradict these conclusions.

Our hypothesis is that these differences in photoreactivity are mainly influenced by the topology of the ${ }^{3} \mathrm{MC}$ surface and by the geometry of the photoreactive states. Following our calculations, we propose the following photosubstitution mechanism: (i) population of the ${ }^{3} \mathrm{MC}_{\text {hexa }}$ state leads to a structure where the $\mathrm{Ru}-\mathrm{S}$ distance is slightly elongated. By staying in the coordination sphere of the metal, the Hmte ligand prevents later access of a solvent molecule to a d orbital of the $\mathrm{Ru}$ atom. In addition, from this ${ }^{3} \mathrm{MC}_{\text {hexa }}$ state, the nonreactive deactivation pathway to the GS is easy due to the accessible ${ }^{1 / 3} \mathrm{MECP}$ crossing point. If a ${ }^{3} \mathrm{MC}_{\text {penta }}$ minimum is present on the ${ }^{3} \mathrm{PES}$, the Hmte ligand undergoes a misalignment and the $\mathrm{Ru}-\mathrm{S}$ bond distance is elongated to such an extent that the $\mathrm{d}$ orbital of $\mathrm{Ru}$ becomes available for the attack of a water molecule. It might be noted that in the ${ }^{3} \mathrm{MC}_{\text {penta }}$ isomer the $[\mathrm{Ru}(\mathrm{tpy})(\mathrm{N}-\mathrm{N})]^{2+}$ moiety recovers a near- octahedral arrangement of the coordination sphere charac- terized by angles between the mean planes of the tpy and N-N ligands around $85^{\circ}$. Thus, it appears that bulky bidentate ligands not only distort the geometry of the complex in the GS but also generate on the ${ }^{3} \mathrm{PES}$ the more reactive ${ }^{3} \mathrm{MC}_{\text {penta }}$ isomer where the misaligned conformation favors ligand exchange. In $[\mathbf{R u} \mathrm{dmbpy}]^{2+}$ the existence of a unique ${ }^{3} \mathrm{MC}_{\text {penta }}$ local minimum with accessible d orbitals facilitates Hmte photodissociation and minimizes nonreactive deactivation pathways, which explains the very high experimental value of $\varphi$.

\section{Conclusion}

The results presented in this work show that discussing the energy level of the d $\sigma^{*}$ or " $\mathrm{e}_{\mathrm{g}}$-like" molecular orbitals of ruthenium polypyridyl complexes in their ground state is not sufficient to predict the effectiveness with which crucial photoreactive ${ }^{3} \mathrm{MC}$ states are populated. Instead, geometry optimization of these triplet states must be achieved, as it is the only way to observe how relaxation from the Franck-Condon geometry may open new pathways on the triplet PES that explain the experimentally observed differences in photoreactivity.

Different mechanistic schemes that allow the photocleavage of the Hmte ligand were identified. Along the reaction path, the intervention of a pentacoordinate ${ }^{3} \mathrm{MC}$ intermediate, the ability for the excited complexes to populate this photoreactive state, and nonradiative 
deactivation toward the GS govern the quantum yields of photosubstitution. The very low quantum yield of photosubstitution reported for $[\mathbf{R u} b p y]^{2+}(\varphi=0.022)$ is explained by the absence of ${ }^{3} \mathrm{MC}_{\text {penta }}$ and a predominant nonradiative deactivation path favored by an accessible ${ }^{1 / 3} \mathrm{MECP}$ from the ${ }^{3} \mathrm{MC}_{\text {hexa. }}$. In contrast, for the highly photoreactive [Ru dmbpy $]^{2+}$ complex $(\varphi=0.30)$, the existence of only one type of photoreactive state, i.e., ${ }^{3} \mathrm{MC}_{\text {penta }}$, favors the formation of a photocleaved intermediate which can easily relax to accommodate a water solvent molecule. The intermediate photosubstitution quantum yields reported for $[\mathbf{R u} \text { biq] }]^{2+}$ and $[\mathbf{R u} \text { dcbpy }]^{2+}(\varphi \approx 0.12)$ result from a combination of the two previous competitive processes. This study highlights the processes that are involved in the first stages of the photosubstitution of the Hmte ligand by a solvent molecule. Our next goal will be to investigate the end of the process, i.e., the formation of the photoproduct (route 2 on Figure 5), in order to ultimately better design metal complexes suitable for medicinal applications. To reach this objective, a molecular dynamics study of the reactivity and of the photoreactivity of this series of complexes in aqueous solution is in progress.

\section{Supporting information}

Cartesian coordinates, energies, and orbitals of all the optimized stationary points, structures of the MECPs, MEPs, and the experimental emission spectrum of $[\mathbf{R u} b p y]^{2+}$ in water

\section{Corresponding Author}

Fabienne Alary. E-mail fabienne.alary@irsamc.ups-tlse.fr

\section{Acknowledgements}

This work was granted access to the HPC resources of the CALMIP supercomputing center under the allocation 2014-[1041] and 2015-[1133]. The NWO (The Netherlands Organization for Scientific Research) and the European Research Council are acknowledged for a VIDI and a Starting grant, respectively, to S.B.

\section{References}

(1) Smith, N. A.; Sadler, P. J. Philos. Trans. R. Soc., A 2013, 371, 20120519.

(2) (a) Knoll, J. D.; Albani, B. A.; Durr, C. B.; Turro, C. J. Phys. Chem. A 2014, 118, 10603-10610. (b) Camilo, M. R.; Cardoso, C. R.; Carlos, R. M.; Lever, A. B. P. Inorg. Chem. 2014, 53, 3694-3708. (c) Welby, C. E.; Rice, C. R.; Elliott, P. I. Angew. Chem., Int. Ed. 2013, 52, 10826-10829. (d) Tu, Y.-J.; Mazumder, S.; Endicott, J. F.; Turro, C.; Kodanko, J. J.; 
Schlegel, H. B. Inorg. Chem. 2015, 54, 8003-8011. Ding, L.; Chung, L. W.; Morokuma, K. J. Chem. Theory Comput. 2014, 10, 668-675. (e) Greenough, S. E.; Roberts, G. M.; Smith, N. A.; Horbury, M. D.; McKinlay, R. G.; Zurek, J. M.; Paterson, M. J.; Sadler, P. J.; Stavros, V. G. Phys. Chem. Chem. Phys. 2014, 16, 19141-19155. (f) Albani, B. A.; Durr, C. B.; Turro, C. J. Phys. Chem. A 2013, 117, 13885-13892. (g) Planas, N.; Vigara, L.; Cady, C.; Miro, P.; Huang, P.; Hammarström, L.; Styring, S.; Leidel, N.; Dau, H.; Haumann, M.; Gagliardi, L.; Cramer, C. J.; Llobet, A. Inorg. Chem. 2011, 50, 11134- 11142. (h) Salassa, L.; Garino, C.; Salassa, G.; Gobetto, R.; Nervi, C. J. Am. Chem. Soc. 2008, 130, 9590-9597. (i) Salassa, L.; Garino, C.; Salassa, G.; Nervi, C.; Gobetto, R.; Lamberti, C.; Gianolio, D.; Bizzarri, R.; Sadler, P. J. Inorg. Chem. 2009, 48, 1469-1481. (j) Borfecchia, E.; Garino, C.; Salassa, L.; Ruiu, T.; Gianolio, D.; Zhang, X.; Attenkofer, K.; Chen; Lin, X.; Gobetto, R.; Sadler, P. J.; Lamberti, C. Dalton Trans. 2013, 42, 6564-6571.

(3) (a) Laemmel, A.-C.; Collin, J.-P.; Sauvage, J.-P. Eur. J. Inorg. Chem. 1999, 1999, 383-386. (b) Bahreman, A.; Limburg, B.; Siegler, M. A.; Bouwman, E.; Bonnet, S. Inorg. Chem. 2013, 52, 9456-9469. (c) Bonnet, S.; Collin, J.-P.; Sauvage, J.-P.; Schofield, E. Inorg. Chem. 2004, 43, 8346-8354. (d) Knoll, J. D.; Albani, B. A.; Turro, C. Chem. Commun. 2015, $51,8777-8780$.

(4) Balzani, V.; Ceroni, P.; Juris, A. Photochemistry and Photophysics: Concepts, Research, Applications, 1st ed.; Wiley-VCH: Weinheim, Germany, 2014, and references therein.

(5) Liu, Y.; Turner, D. B.; Singh, T. N.; Angeles-Boza, A. M.; Chouai, A.; Dunbar, K. R.; Turro, C. J. Am. Chem. Soc. 2009, 131, 26-27.

(6) Rotzinger, F. P. Chem. Rev. 2005, 105, 2003-2037.

(7) Frisch, M. J.; Trucks, G. W.; Schlegel, H. B.; Scuseria, G. E.; Robb, M. A.; Cheeseman, J. R.; Scalmani, G.; Barone, V.; Mennucci, B.; Petersson, G. A.; Nakatsuji, H.; Caricato, M.; Li, X.; Hratchian, H. P.; Izmaylov, A. F.; Bloino, J.; Zheng, G.; Sonnenberg, J. L.; Hada, M.; Ehara, M.; Toyota, K.; Fukuda, R.; Hasegawa, J.; Ishida, M.; Nakajima, T.; Honda, Y.; Kitao, O.; Nakai, H.; Vreven, T.; Montgomery, J. A., Jr.; Peralta, J. E.; Ogliaro, F.; Bearpark, M.; Heyd, J. J.; Brothers, E.; Kudin, K. N.; Staroverov, V. N.; Kobayashi, R.; Normand, J.; Raghavachari, K.; Rendell, A.; Burant, J. C.; Iyengar, S. S.; Tomasi, J.; Cossi, M.; Rega, N.; Millam, J. M.; Klene, M.; Knox, J. E.; Cross, J. B.; Bakken, V.; Adamo, C.; Jaramillo, J.; Gomperts, R.; Stratmann, R. E.; Yazyev, O.; Austin, A. J.; Cammi, R.; Pomelli, C.; Ochterski, J. W.; Martin, R. L.; Morokuma, K.; Zakrzewski, V. G.; Voth, G. A.; Salvador, P.; Dannenberg, J. J.; Dapprich, S.; Daniels, A. D.; Farkas, Ö.; Foresman, J. B.; Ortiz, J. V.; Cioslowski, J.; Fox, D. J. Gaussian 09, Revision A.1; Gaussian, Inc., Wallingford, CT, 2009. 
(8) Neese, F. ORCA - an ab initio, DFT and semiempirical program package, Version 2.9; University of Bonn, Bonn, Germany.

(9) (a) Runge, E.; Gross, E. K. U. Phys. Rev. Lett. 1984, 52, 997. (b) Perdew, J. P.; Burke, K.; Ernzerhof, M. Phys. Rev. Lett. 1996, 77, 3865. (c) Perdew, J. P.; Burke, K.; Ernzerhof, M. Phys. Rev. Lett. 1997, 78, 1396. (d) Adamo, C.; Barone, V. J. Chem. Phys. 1999, 110, 6158. (10) (a) Grimme, S.; Antony, J.; Ehrlich, S.; Krieg, H. J. Chem. Phys. 2010, 132, 154104. (b) Grimme, S.; Ehrlich, S.; Goerigk, L. J. Comput. Chem. 2011, 32, 1456-1465.

(11) Schäfer, A.; Horn, H.; Ahlrichs, R. J. Chem. Phys.1992,97, 2571-2577.

(12) Martin, J. M. L.; Sundermann, A. J. Chem. Phys. 2001, 114, 3408-3420.

(13) Göttle, A. J.; Alary, F.; Dixon, I. M.; Heully, J.-L.; Boggio- Pasqua, M. Inorg. Chem. 2014, 53, 6752-6760.

(14) Tomasi, J.; Mennucci, B.; Cammi, R. Chem. Rev. 2005, 105, 2999-3093. (b) Scalmani, G.; Frisch, M. J. J. Chem. Phys. 2010, 132, 114110.

(15) Klamt, A. J. Phys. Chem. 1995, 99, 2224-2235.

(16) (a) Dreuw, A.; Head-Gordon, M. Chem. Rev. 2005, 105, 4009. (b) Martin, R. L. J. Chem. Phys. 2003, 118, 4775.

(17) Henkelman, G.; Jonsson, H. J. Chem. Phys. 2000, 113, 9978- 9985.

(18) Weinan, E.; Ren, W.; Vanden-Eijnden, E. J. Chem. Phys. 2007, 126, 164103-164108.

(19) Valiev, M.; Bylaska, E. J.; Govind, N.; Kowalski, K.; Straatsma, T. P.; van Dam, H. J. J.; Wang, D.; Nieplocha, J.; Apra, E.; Windus, T. L.; de Jong, W. A. Comput. Phys. Commun. 2010, 181, 1477.

(20) Bossert, J.; Daniel, C. Coord. Chem. Rev. 2008, 252, 2493-2503.

(21) Alary, F.; Heully, J.-L.; Bijeire, L. Inorg. Chem. 2007, 46, 3154-3165.

(22) (a) Göttle, A. J.; Dixon, I. M.; Alary, F.; Heully, J.-L.; Boggio- Pasqua, M. J. Am. Chem. Soc. 2011, 133, 9172-9174. (b) Lebon, E.; Bastin, S.; Sutra, P.; Vendier, L.; Piau, R. E.; Dixon, I. M.; Boggio- Pasqua, M.; Alary, F.; Heully, J.-L.; Igau, A.; Juris, A. Chem. Commun. 2012, 48, 741. (c) Piau, R. E.; Guillon, T.; Lebon, E.; Perrot, N.; Alary, F.; Boggio-Pasqua, M.; Heully, J.-L.; Juris, A.; Sutra, P.; Igau, A. New J. Chem. 2012, 36, 2484-2492. (d) Lebon, E.; Sylvain, R.; Lanthony, C.; Pilme', J.; Sutra, P.; Boggio-Pasqua, M.; Heully, J.-L.; Alary, F.; Juris, A.; Igau, A. Inorg. Chem. 2014, 53, 1946-1948.

(23) Su, J. H.; Cox, N.; Ames, W.; Pantazis, D. A.; Rapatskiy, L.; Lohmiller, T.; Kulik, L. V.; Dorlet, P.; Rutherford, A. W.; Neese, F.; Boussac, A.; Lubitz, W.; Messinger, J. Biochim. Biophys. Acta, Bioenerg. 2011, 1807, 829-840.

(24) Hammond, G. S. J. Am. Chem. Soc. 1955, 77, 334-338. 
(25) Bessel, C. A.; Margarucci, J. A.; Acquaye, J. H.; Rubino, R. S.; Crandall, J.; Jircitano, A. J.; Takeuchi, K. J. Inorg. Chem. 1993, 32, 5779-5784.

(26) Charton, M. J. Am. Chem. Soc. 1975, 97, 1552-1556. 